\title{
ON A TRIGEMINAL-AURAL REFLEX IN THE RABBIT.
}

BY SIR VICTOR HORSLEY, F.R.S., F.R.C.S.,

Surgeon to University College Hospital, and the National Hospital for th: Paralysed and Épileptic.

IT is well known that if a wild rabbit is feeding quietly its ears lie horizontally along its back, but that when startled it raises itself upright by extending its spine and then erects its ears.

This last movement of the ears has always been regarded as voluntary, i.e., a high purposive act on the part of the animal to detect a source of danger. I have found, however, that such a protective elevation of the ear can also be produced as a simple reflex movement evolied by excitation of only one branch of the trigeminal nerve, namely, the infraorbital. Of the following photographs, taken at the rate of $\frac{1}{10} \overline{0}$ th of a second, the first shows in a young wild rabbit the ears in a position of rest. (I may remark parenthetically that such a little rabbit, even recently caught, will keep quiet for a long time in the warm hand if it is gently stroked, as shown in the photographs).

Photographs 2 and 3, a side and front view respectively, show that when the vibrissæe on the infra-orbital region are gently touched with the finger, or the skin of that part gently pressed (especially over the infra-orbital foramen), the homolateral ear alone is raised up vertically and som:what rotated forwards.

Photograph 4 shows that the elevation of the ear is tonic and persists for several seconds after the stimulus is removed; the ear then slowly subsiding to the horizontal position.

If the animal was startled and resented th. touch of the finger, the contralateral ear was also raised, and the rabbit.

VOL. XXVIII. 
escaped as shown in Photograph 5, where the hind quarters are shown rising in the action of leaping.

It being obvious that the psychical stimulus of fear caused the bilateral general reaction, I tested other afferent paths when the rabbit was quieted. The results were wholly negative except as regards auditory stimuli. Thus, Photograph 6 shows the ears of the rabbit quite quiet although a ray of direct sunlight is reflected on to its eye ; the only result being some protective contraction of the orbicularis oculi muscle. Similarly touch or pressure stimuli applied to the other parts of the body were without effect on the ear.

Pricking of the ears being undoubtedly associated with an appreciation of danger, it is reasonable that it should occur when the infra-orbital region, and especially the vibrissæ, are touched; since a rabbit in escaping from danger encounters numerous obstacles as it runs in the depths of the burrow, or through bushes and grass in the dark, and therefore must largely rely on contact impressions from its face.

Though most active in the wild animal I have obtained this reflex also in tame and albino rabbits, even whether partly lop-eared or no.

Next, as regards the localisation of this reflex movement, the phenomenon is analogous to the representation of the movements of the ear in the inferior colliculis (corpus quadrigeminum posterius), and that the motor path is the same for the auditory and infra-orbital reflexes, inasmuch as the movement executed by the pinna is identical, namely, elevation with rotation so as to present the conchal concavity forwards and outwards.

On the question of the localisation of movements of the ear, Ferrier ${ }^{1}$ was the first to find that excitation of the anterior colliculi produced, in addition to movements of the eyes, marked "retraction of the ears," and that the same occurred on stimulation of the posterior colliculi.

V. Bechterew ${ }^{2}$ similarly obtained by excitation of both the anterior and posterior colliculi turning of the contralateral ear outwards, in addition to conjugate deviation of 
the eyes to the opposite side, \&c. In a later paper ${ }^{1}$ he stated (p. 711) that after unilateral destruction of the posterior colliculus in a rabbit the animal did not prick up the contralateral ear nor turn towards a source of sound.

Prus, ${ }^{2}$ in his valuable paper on excitation of the colliculi in dogs, describes the movement of the ear in connection with stimulation of the anterior colliculus only.

Ziehen's ${ }^{3}$ observations also coincide with the foregoing results, as also do certain observations by Thiele, which will shortly be published.

During recent years I have made many observations on excitation of the colliculi, anterior and posterior, especially in conjunction with Dr. Magnus during 1904; and in the cat, dog and monkey have observed, in confirmation of Ferrier, that faradic excitation of the outer surface of the posterior colliculus evokes, besides the rotation downwards of the homolateral eye (fourth nerve effect), marked rotation of the pinna of the contralateral ear. The same result was also obtained after section (whether made immediately or three weeks before the excitation) of the intercollicular commissure. The localisation of the phenomenon is therefore exact. Not infrequently the homolateral rather than the opposite ear moves, but the character of the movement is the same, viz., rotation for better audition, an action very different from the flattening and setting back of the pinna as a protection in fighting, which latter can be obtained from a wide area of the cortex cerebri in all animals, notably the ungulata. As, of course, the representation of the cochlear nerve in the posterior colliculus is now definitely established, the similar association with the fifth nerve of the "auditory" movement of the pinna, which evidently is of a defensive and useful character, is easy to understand.

\footnotetext{
1 Neurologisches Centralblatt, 1895, vol. xiv., p. 706.

2 Wiener Klinische lochensclerift, 1899, No. 45, p. 1,124.

3 Archiv. fur Psychiatrie und Nerienheilhunde, rol. xxi., p. 863.
} 